\title{
(in)visible bodies and (de) contextualization: A critique of the Independent Review of Cathedral Valley Group Home.
}

\author{
Sheila Grantham \\ $\mathrm{PhD}$ student, Indigenous and Canadian Studies, Carleton University
}

\begin{abstract}
The Report on the Independent Review of Cathedral Valley Group Home (Tuckett, 2010) was commissioned by the Minister of Family Services and Consumer Affairs due to allegations by former Indigenous residents who claimed that various forms of exploitation had occurred. The home was operational in the 1970's and early 1980's in Manitoba and although non-Indigenous children and youth resided in the home, the majority of its residents were Indigenous. While the Report on the Independent Review of Cathedral Valley Group Home was an attempt to evaluate the treatment of the residents that stayed at the group home, it further marginalizes the voices of those Indigenous residences through narratives that de-race, decontextualize and privilege nonIndigenous voices.
\end{abstract}

Keywords: Sixties Scoop, racism, reconciliation, redress

\section{Introduction}

The following paper critically examines the Cathedral Valley Group Home Report (CVGH) commissioned by the Manitoba government. This revealing case study highlights broader systemic implications that undermined the experience of certain Indigenous children and youth within the child welfare system in an era known as the Sixties Scoop. Specifically, it rendered invisible the Sixties Scoop and the experiences that are attached to such a term by placing these experiences outside an era Judge Kimelman (1985) unequivocally recognized as "cultural genocide". Furthermore, the report is riddled with misnomers of underlying ideologies of racism that are colonizing and silencing the Indigenous voice, reinforcing notions of cultural superiority and imperialism. Despite the determination that something "not quite right" had transpired at the $\mathrm{CVGH}$, this anomaly was not fully defined nor addressed in the apology.

Several news sources such as the Winnipeg Free Press, $C B C$, and Toronto Sun have published a series of articles on the Indigenous experiences within the CVGH in Manitoba. The articles spoke of the "Warriors of the Lost Boys", which is comprised of former group home residents led by Sam McGillivary, who had been lobbying for an inquiry into the CVGH and 
sought restitution for harms suffered (Gosek, 2008). McGillivary spoke of how once placed in the CVGH, Indigenous children and youth were subjected to slave labour as well as physical and sexual abuse (Brodbeck, 2008). Similar to McGillivary's experience, extreme poverty and/or addictions are common reasons for Indigenous children and youth to become entangled within the child welfare system (Brodbeck, 2008). Certainly, the aftermath of residential schools left many communities and families in a state of dysfunction and without the tools, support and resources to protect themselves from the next wave of colonial intrusions through the Sixties Scoop.

Although McGillivary has openly expressed his experiences of trauma at the CVGH, the group home experience during the era of the Sixties Scoop remains largely unexamined. According to Kimelman (1985), many children and youth that should have entered foster homes or placed for adoption were sent to group homes during the period known as the Sixties Scoop in Manitoba. Group homes allowed for greater flexibility in the number of children permitted to reside within a single home as opposed to the instituted restrictions for foster homes. Children and youth entering into these homes were relinquished by their families or apprehended by Child and Family Services. The only literature that dealt with Indigenous children within foster group homes in Manitoba is The Group Home Report (1985) found within the Kimelman Inquiry and The Report on the Independent Review of Cathedral Valley Group Home (2010) commissioned by the Manitoba Family Services and Consumer Affairs to examine a particular foster group home within the era of the Sixties Scoop (Tuckett, 2010). In both documents, issues of trauma were not documented as many group homes were not thoroughly examined. The CVGH report was produced after former Indigenous group home residents protested against the Manitoba government, claiming they were forced into slavery and suffered physical, sexual, and emotional abuse while residing in the group home. Not only were the former Indigenous residents calling for justice, accountability and compensation, the Assembly of First Nations National Chief at that time, Phil Fontaine, echoed the need for and importance of an inquiry. Increased pressure on the Manitoba government came after Sam McGillivary camped outside of the Winnipeg Legislature building for thirty-one days, which garnered increased attention amongst the media and Indigenous groups and eventually led to the province's decision to conduct an 'independent' review on which the CVGH report was later based (Kusch, 2010). The report led to the subsequent apology by the province, albeit concluding that there were residents who benefitted from their experience in the group home while there were other (Indigenous) former residents who were harmed emotionally (Tuckett, 2010)). According to the independent review led by the former Provincial Ombudsman of Manitoba Barry Tuckett, he concluded that perhaps the home was merely not the right 'fit' for some of the children and youth who had resided there and individual healing plans were said to be made available for those former residents (Tuckett, 2010). This narrative speaks to a very subjective view that situates some of the (Indigenous) former residents as contributing to the 'problem' and infers that no real problem would have existed if it were not for their claims of abuse and their participation in the home. Who benefits 
from such messages relayed in this report? What ideologies are being reinforced through the use of certain terms? Lastly, what is implicitly excluded?

\section{Methodology}

The CVGH report is viewed in this analysis through a lens that is cognizant of race, while approaching the research through a method that privileges Indigenous voice. Critical race theory examines how there are many sites of oppression as society is socially constructed based on hierarchy, race, gender and differing abilities (Delgado and Stefancic, 2012). A critical race approach to this research assists in questioning idealistic notions of equality that do not factor in the experiences of those who have been historically marginalized due to their race.

As a social construct, race only serves to benefit those who are considered "race-less" (Delgado and Stefancic, 2012). For example, the word Anishinaabe speaks to a connection that those Indigenous peoples have to the land as the original peoples of Turtle Island. Community and land are interconnected to the identities of many Indigenous peoples. Colonization, imperialism and assimilation in Canada have had destructive effects on Indigenous peoples, separating them from land, community and families through assimilatory policies such as residential schools and later through assimilatory procedures such as the Sixties Scoop. Through this separation, there is a need to remember and retrieve all aspects of ourselves as Indigenous peoples; including how we are perceived and how we reconcile the past. As Smith argues (1999)

To acquiesce is to lose ourselves entirely and implicitly agree with all that has been said about us. To resist is to retrench in the margins, 'retrieve what we were and remake ourselves'. The past, our stories local and global, the present, our communities, cultures, languages and social practices- all may be spaces of marginalization, but they have also become spaces of resistance and hope. (p.4)

Resistance to hegemony requires that we are able to share our stories, remembering loss yet understanding our inner strengths and overall resiliency. Throughout this paper, I hope to privilege an Indigenous presence (ibid, p.6) and find ways to "talk back" (p.7) or resist narratives that attempt to silence Indigenous experience.

\section{Situating my voice in this research}

In my Master's research, I wanted to understand the myriad of experiences Indigenous peoples faced in the child welfare system during the era known as the Sixties Scoop as this is an area that has greatly impacted my family and, by extension, myself. Reflected in one of the interviews and throughout my time speaking to Sixties Scoop survivors in Manitoba, I encountered individuals who had faced abuse within their group home setting. However, the 
group home experience was largely left unexamined except for $A$ Report on the Independent Review of Cathedral Valley Group Home (Tuckett, 2010). As the title suggests, it only speaks minimally to certain perceived experiences within this one group home. This article discusses the report's findings, analyzes what ideologies the report reflects, considers what is not being discussed or included and suggests ways forward that address issues of justice. In examining the report, a dialogue can begin that leads to a more thorough examination on the subject of group homes that may lend itself to more inclusive interpretations and experiences of Sixties Scoop survivors.

Waaskones nindizhinikaaz makwa dodem. I am both Métis and non-status Anishinaabekwe, (despite common misnomers inherent in Indian Act definitions of who is and who is not deemed an "Indian"). As well, I have Black and Welsh ancestry, (which somehow is easily digestible outside of the sphere of Indigenous identity politics of recognition). Aside from introducing my legal name, spirit name and ancestry, I feel as an "academic" conducting research involving Indigenous people that I should discuss the significance and connection I have to the topic at hand. In sharing my journey in how I came to the decision to do research on the topic of the Sixties Scoop, I hope to be able to provide a deeper level of understanding that can assist in contextualizing my intentions and involvement in this process.

Residential schools and the child welfare system have impacted both sides of my family and the intergenerational effects of such experiences have had an impact on me as well. I came to understand that most of my family has been socialized to think of oppression as a normalized state and/or part of their daily experiences as Indigenous peoples. Together, we all live with the trauma that oppression brought into our lives and very few question its unacceptability. In discussing past traumas, I hoped to help myself, my family and all those involved acknowledge the unacceptability of the past and continue to move forward in positive ways in addressing it. Research is more than just a student submitting a paper; "it goes beyond the idea of individual knowledge to the concept of relational knowledge...you are answerable to all your relations when you are doing research" (Wilson, 2008, p.56-57). With this point in mind, the experiences of my ancestors are intertwined with my life and those who I love. As such, I felt a need to see if others also had similar lived experiences, direct or indirect, within the era of the Sixties Scoop. In shedding light on these experiences, I am sharing both the stories of the participants and my relations by showcasing our interconnectivities and strengths as Indigenous survivors. What I did find in my research was how overlooked and unacknowledged were the experiences Indigenous children faced during the era of the Sixties Scoop within foster group homes in Manitoba and, subsequently, how those experiences were not reflected in the public discourse around the Sixties Scoop. 


\section{Decontextualized: The Sixties Scoop}

The Sixties Scoop has become known as one of the most pervasive actions impacting Indigenous communities with wide-ranging effects throughout the country and beyond (Kimelman, 1985). There were more Indigenous children leaving their communities and families and entering into the child welfare system than at the height of residential schools (Obomsawin, 1986). Although the CVGH was in operation during this time-frame and there were more Indigenous children and youth in the home than non-Indigenous children and youth, the Sixties Scoop phenomenon was largely dismissed. By separating the Sixties Scoop from the events transpiring within the $\mathrm{CVGH}$, the report decontextualizes the experiences that many Indigenous children and youth were facing at that time (Tuckett, 2010). The report is located outside of the realm of experiences that spoke to the large-scale loss of family, community and culture that echoed issues of racism, exploitation and sexual and physical abuse. As such, in my attempt to re-centre and contextualize the discourse of the $\mathrm{CVGH}$, it is prudent and necessary to provide further context to the Sixties Scoop.

Indigenous children have been, and continue to be, over-represented within Canada's child welfare system (Government of Canada, 2008). Many were placed in the care of social services between 1950 and the early 1980s and faced separation from their families and communities. Some claimed to have experienced a loss of language and culture. Although some had positive experiences (Swidrovich, 2004), others were traumatized by experiences of exploitation and abuse in their placements. This phenomenon is known as the Sixties Scoop. The Sixties Scoop can be seen as assimilationist and an ongoing form of colonialism (Sindelar, 2004, p.9). The Royal Commission on Aboriginal Peoples (RCAP) reported that social workers involved in the Sixties Scoop believed they were acting in the best interest of Indigenous families by separating children from their parents and extended family (Kimelman, 1985, p.276).

Between 1946 and 1948, the Canadian Welfare Council and the Canadian Association of Social Workers prepared a joint brief highlighting the inequitable situation that Indigenous peoples faced across the country (Fournier and Crey, 1997). The brief stated that First Nations children were not receiving the same care or services as other Canadians (ibid, p.83). At the time, the provinces lacked the authority to deal with situations of apprehension and increasingly, residential schools were functioning as a child care institution rather than for "educational" purposes (Milloy, 1999). Children in need were often relegated to the supervision of Indian Affairs employees. Frequently, children left in situations of neglect were sent to residential schools instead of being placed in a home setting. Many issues arose as a consequence of the federal government's failure to provide social welfare services to Indigenous peoples. It was these discussions that ultimately led to the transfer of authority of Indigenous child welfare services to the provinces. 
In 1951, amendments to child welfare services occurred and the federal government transferred authority for services involving on-reserve Indigenous peoples to the provincial governments, although the federal government still maintained its authority over issues that involved treaties and other federal laws (Walmsley, 2005; Fournier and Crey, 1997). The provinces, however, seemed hesitant to enter reserves unless for serious life or death matters and, when they did, no support services or follow-up were provided because reserves fell outside their jurisdiction (Johnston, 1983). In fact, the federal government did not readily fund the provinces for the extension of services until the late sixties; although separate agreements were signed with various provinces at different times.

\section{Child Welfare Services in Manitoba}

In 1966, the federal government brokered an agreement with the province of Manitoba to reimburse all costs relating to the extension of services to on-reserve populations. In addition, a separate amount was allocated for unmarried mothers. It seems that two different policy agreements within the province left one region receiving more child welfare services than the other. Within the central and northern regions, where $75 \%$ of all First Nations bands reside in Manitoba, there were limited services provided to these communities (Johnston, 1983). However, First Nations communities in the southern area of Manitoba had access to many more services offered by the Child and Family Services at that time including those funds targeted for unwed mothers (Johnston, 1983). Subsequently, funding was not allocated to the provinces for the delivery of child welfare for non-status and Métis peoples. (Johnston, 1983). Despite this disparity, both non-status and Métis children faced many adverse experiences and have been impacted through the historical legacy of residential schools and other assimilatory policies and procedures.

Although an agreement was in place for the transfer of child welfare services, it was not until later that the federal government also agreed to extend full compensation to various provinces for the transfer of such services. For example, funding in Manitoba was allocated between 1962 and 1964 for Societies of Western, Eastern and Central Manitoba (Hawthorne, 1966). In Northern Manitoba, welfare authorities did not service Indigenous children. Due to the child welfare agreements amongst the societies, one-fifth of the Indigenous population was left without child welfare services (Hawthorne, 1966). However, prior to receiving funding to extend its services onto reserves, social services were already providing services to First Nations communities (Hawthorne, 1966).

Despite varying provincial agreements with the federal government, Indigenous children, including those on-reserve, became largely over-represented within the child welfare system during the late sixties and onwards (Hepworth, 1985). In 1959, Indigenous peoples only represented $1 \%$ of the total population of children within the child welfare system; within ten 
years, that figure rose to $30-40 \%$ eventhough Indigenous children comprised less than $4 \%$ of the total population at the time (Fournier and Crey, 1997). Depending on the area and province, the proportion of children entering into the child welfare system varied; however, what is consistent is how disproportionate the statistics are versus the non-Indigenous populations from Ontario extending westward. In Manitoba, these cases of maltreatment and dysfunction within the child welfare system are well documented in the Kimelman Inquiry (1985), which led to a moratorium on all out-of-province Indigenous adoptions and a growing desire from Indigenous communities to keep Indigenous children within Indigenous homes.

\section{Group Homes}

According to Kimelman (1985) and cited within the CVGH report, Canadian group homes emerged within the 1940s to provide another option in place of foster care. In the province of Manitoba, the demand and utilization of group homes increased in the 1970s (Tuckett, 2010). As Kimelman (1985) notes, children who were deemed 'problematic' and unable to adapt in a family setting or who had a foster/adoption breakdown were often placed in group home settings (p.251-252). Social workers, at times, provided limited follow up for children or youth who entering into a group home setting (ibid). It was often seen as easier for social workers to place children and youth into group home settings regardless of whether it was an appropriate fit or not. These group homes were privately or publicly run.

Group homes had developed under a variety of auspices. Private profit-making groups, non-profit organizations, child-care agencies, and institutions were establishing group homes without coordination and without consideration of the extent of the need or where such homes were required. No standards were in place for monitoring the safety, or the program content, of these group homes. (Kimelman, 1985, p. 220-221)

There was no specific training for those operating group homes during the 1970s, despite the increased trend of Indigenous children and youth entering these spaces. Kimelman (1985) notes that there was a "lack of sensitivity" held for children and youth of certain "ethnic/cultural backgrounds" residing in these homes (p. 257). During this era, there were very few Indigenous employees working in group homes (ibid, p.320) and these homes were largely run by individuals who may not have had prior knowledge or experience working with Indigenous peoples.

Too many group homes stood out as shabby, neglected, requiring basic repair and daily attention. The interiors of these homes were usually compatible with the exterior. Minimum furniture, no curtains or drapes, no plants, no pictures, nothing aesthetically pleasing. Many rooms left the impression of a badly run boarding house. (Kimelman, 1985, p.308) 
Kimelman (1985) suggests that some children were psychologically harmed within group home settings and in these instances, he recommended the group home to be shut down (p.310).

\section{Cathedral Valley Group Home Report}

“...settler perspectives and worldviews get to count as knowledge and research and... these perspectives - repackaged as data and findings - are activated in order to rationalize and maintain unfair social structures" (Tuck and Yang, 2012, p. 2).

The CVGH report offers a narrative of Henry Blake, a man who volunteered his time as a Scout Master and who assisted an elderly war veteran by helping him on his farm (Tuckett, 2010, p.11). Blake purchased land in the late 1960s near Riding Mountain where he received the assistance of his Scout troop to clear the land and build his house (ibid).

Henry approached family services in 1970 and proposed a structured group home in which the residents of the home would take care of animals to be sold for profit (ibid, p.11). Upon sale of these animals, he claimed a part of the proceeds would be given to the children and youth residing at the group home. At this time, there were no group foster homes in the area. The home was initially designated as a foster home, but shortly thereafter it was authorized as a group home (ibid, p.12). Foster homes were only allowed to have four children/youth in their occupancy at any given time, yet the CVGH had nine to ten boys residing in the group home from 1972-1974. According to Tuckett (2010), "the residents came from homes where they were not receiving the care they required or were involved in delinquent activities and they needed protection or a supervised environment" (p. 21). The group home was run jointly with Blake's wife Phyllis who was a physiotherapist (Tuckett, 2010, p. 11).

Henry and Phyllis Blake operated the home until 1977 when she was tragically murdered by one of the Indigenous youth (resident "U") who wanted to flee the home (Tuckett, 2010). The CVGH report shares the experiences of resident " $U$ " through the lens of court documents and probation officers, recanting the physical abuse he had experienced by Henry Blake and how unhappy he had been in that placement. In the CVGH report, the profile of resident " $U$ " is summed up with claims that the placement of the resident in the CVGH was a mistake and that his personality and dissatisfaction led him to bottle up his emotions, resulting in the explosion that culminated in Phyllis Blake's death (ibid, p.43). Resident "U" was convicted and sentenced to second-degree murder. After the death of Phyllis Blake, Henry Blake remarried to his second wife, Barb Blake; she continued to operate the home after his death in 1982 (ibid, p.14). The group home formally closed in 1983.

Although Phyllis Blake had been murdered at the $\mathrm{CVGH}$, an inquiry emerged 30 years later due to pressures from former Indigenous residents of the home. The inquiry into the group 
home is largely credited to the Warriors of the Lost Boys (Gosek, 2008). In 2008, the province of Manitoba announced they would launch an inquiry into Cathedral Valley; Barry Tuckett was selected to lead the inquiry resulting in the report. The inquiry concluded with Tuckett requesting supports for some of the (Indigenous) former residents:

This review has led me to the conclusion that there remains a need for recognition of the emotional damages suffered by some of the boys. Their removal from their families and communities and the resultant feelings they inevitably felt of fear, isolation, abandonment, loneliness and confusion were exasperated by their experiences at $\mathrm{CVGH}$, which for some may have included physical and sexual abuse. There needs to be healing, a process for healing, and a plan to provide it (Tuckett, 2010, p.62).

The CVGH report focuses mainly on emotional harms caused to some of the former residents. As Tuckett claims, there was not enough evidence to substantiate allegations of slave labour, physical and/or sexual abuse. Based on Tuckett's findings, Gord Mackintosh, Manitoba Minister of Family Services and Consumer Affairs, provided what the Winnipeg Free Press calls a "quick apology" in 2010 for emotional harms that some of the former residents may have suffered (Kusch, 2010).

Although a more concerted effort could have been made to apply a critical race lens to the research conducted, the CVGH report does mention that there were more Indigenous than non-Indigenous children (Tuckett, 2010, p. 21). Through the inquiry, former residents were provided an opportunity to allow their stories to be heard and attempts were made to involve the stories of those who had passed on (i.e. resident "C", "D", "K"). This inquiry led to an official apology and an offer of emotional supports to some former residents. An apology is a form of acknowledgement that something not quite right had transpired at the $\mathrm{CVGH}$, eventhough that which was seen as "not quite right" was not fully defined nor addressed. However, the question remains as to what extent the report acknowledges Indigenous experiences in the CVGH? What exactly is validated through the apology? More importantly, what is being denied?

\section{Indigeneity and Invisibility}

By all accounts, Henry Blake is characterized as an upstanding Christian white male citizen who volunteers much of his time helping children as well as a "gentlemanly" elderly (likely Caucasian) war veteran. Blake's image is further reified by his wife, Phyllis Blake, who had a reputable career as a physiotherapist. All of these details come into greater focus and help to identify what is deemed as normal versus the periphery of experiences left voiceless by those participants seemingly rendered race-less throughout the report as they are labeled as name-less resident "A" through "U". Furthermore, the report does not take into consideration how 
pervasive colonization, imperialism, and racism have been, and continues to be, within the lives of Indigenous peoples all over Canada. It does not consider that the group home was operating at a time known by many as the Sixties Scoop, when there was an over-representation of Indigenous children entering into the child welfare system, especially within Manitoba. Moreover, the former group home residents that claim abuse within Cathedral Valley are Indigenous and there are other forms of evidence throughout the report that imply that the treatment of Indigenous children and youth by the group home operator was worse than that of the non-Indigenous residents. Consequently, many of the former Indigenous children and youth who attended the home continued to face trauma from their time spent at Cathedral Valley, as exemplified within the accounts of former Indigenous residents themselves. Furthermore, it was found that at least three of the former residents had committed suicide. With regard to Resident" U", who was charged in the killing of the group home operator's wife, he was Indigenous yet he was not interviewed nor were his relatives. This leads to a further silencing of the Indigenous survivors' experiences. Similar to the other Indigenous residents who speak of stories of abuse, the onus for such dysfunctional claims of abuse and trauma had been placed on the Indigenous children and youth themselves. This insinuated that there must be something inherently 'wrong' with them, ignoring their testimonials (while simultaneously refuting and silencing claims that various forms of violence had been occurring in the home). Henry Blake became "a man entitled to the land and the full benefits of citizenship" (Razack, 2002, p.126). The land can be seen as a metaphor for the Indigenous body and the full benefits of citizenship is the realm in which violence has been routinely accepted and excused in the lives of Indigenous people (ibid, p.125).

Finally, the CVGH report segregates itself from what was transpiring outside of its doors, largely noted within the discourse on the Sixties Scoop, and decontextualized the experiences from the era from which it emerges. Also, the report has demonstrated a 'de-racing' of identities through its profiling, yet Indigenous residents are situated in spaces of (un)credibility. The next section explores how the CVGH chose to un/name $e^{\mathrm{ii}}$ and emphasize stereotypes rooted in racist ideologies while rendering invisible Indigenous experiences.

The CVGH report situates Indigenous voices as needing certain types of proof in order to be legitimated as an occurrence. The report dismisses the experiences of those who claimed to have faced slave labour, sexual and physical abuse. It only says that the Manitoba government is sorry for emotional abuse that some may have suffered without specifically naming who this represents. The Indigenous body represents, in this case, a space that is seen as inherently guilty and is quickly dismissed as unauthoritative and incapable of understanding their own lived experiences whereas the white body (Razack, 2002, p. 128) as represented through the narratives told of the group home operators, the probation officers, community members and social workers, are upheld as superior. 
The CVGH Report contains interviews with a variety of individuals. Only nine former residents were interviewed while 18 external parties and 24 former probation officers and social workers affiliated with the group home were interviewed (Tuckett, 2010). Overwhelmingly the inquiry relied heavily on the "expert" witnesses of social workers and probation officers to corroborate evidence as "truthful" and dismiss others as not substantive enough.

\section{Cowboys versus Indians}

He had a military background, and was heavily involved in the Scouting movement throughout his life. Based on interviews with the residents, neighbours, community people and government employees, one could describe Mr. Blake as a big man, with a rough and imposing personality. Some described Mr. Blake as a "John Wayne" type of character. Mr. Blake was also described as an overbearing and intimidating man who was a firm believer in strict rules, obedience, discipline and punishment. It was suggested that Mr. Blake believed that structure, hard work and discipline were good for the residents in terms of character building. (Tuckett, 2010, p.17)

Based on individual accounts of those who did not reside in the household, Henry Blake was described as having previous experience in the military and was quite active in scouting; he was seen as rough and imposing, similar to the likes of "John Wayne" (Tuckett, 2010). Through his "overbearing" and "believer in strict rules, discipline and punishment", he held certain moral values that "structure, hard work and discipline" built character (ibid, p.17). The imagery of Mr. Blake speaks to the iconic "heroic" cowboy who is rough around the edges but believes in civility, law and order. By contrast, the very report investigating the treatment residents experienced in the home masks their identities by naming them as letters of the alphabet devoid of any positive character attributes.

Indigenous peoples never viewed the land as wild and themselves as uncivilized. It was not until Hollywood narratives of Cowboys and Indians, as represented by actors such as John Wayne, that Indigenous peoples began to find themselves situated in the civilized/savage binary (Larocque, 2004). As Larocque (2004) argues, the "Indian" in relation to the Cowboy becomes distorted, existing in a fictional space outside of the realm of reality, but deeply rooted in racism:

Although mainstream Canadians have worked out (and are still working out) their trek west quite differently than Americans with respect to Aboriginal people, they have nonetheless espoused much of the western heroism and frontierism abundant in American history and popular culture. There is an intimate connection between racism and the Wild West/frontier thesis. In other words, Cowboy/Indian movies are one significant aspect of institutionalized racism (p.141) 
Larocque speaks of the 'hero-fiction', which promotes the valorization of the cowboy killing the Indian, associating these actions as contributing to "moral, cultural and racial progress" and distinguishing who is seen to be legitimated by the narrative, as it assumes the role of the Other as wild or savage (ibid, p.141).

Those claiming abuse represent a space of deviancy as former Indigenous group home residents. Reflected in their experiences are encounters of violence, a space far removed from the group home operator and his wife. In order to continue to maintain the benefits of power and imperialism, disguised as "order and civility", the story then must reassert notions of Indians as savage and Cowboys as heroic. The CVGH report and inquiry, which were initially meant to investigate former Indigenous residents and abuses suffered at the hands of the group home operators, then transforms and morphs into the narratives surrounding the murder of Phyllis Blake and the horror that the group home residents felt in witnessing its aftermath. The reasons for the inquiry by the Indigenous residents is reinterpreted or dismissed, banishing all Indigenous claims of racialized violence. The group home operators are the victims and the Indians maintain their status as the villains.

\section{Race(ism)}

Ruth Frankenberg... argues that in such contexts white women aspire to 'not see' race difference despite its continued salience in society and in their own lives (Frankenberg 1993; 149), she devised methods for naming the unnameable, marking the unmarked, seeing the invisible, or, more importantly, articulating the meaningfulness of its carefully constructed meaninglessness. (Twine and Warren, 2000, p.20)

As discussed, all former group home residents profiled within the study were referred to by a letter. Although there are some identifying remarks made within the report, no descriptions were provided of whether the former residents were First Nations, (and/or) Metis, (and/or) Inuk. It is also worthy to note the absence of narratives of those individuals who did not participate in the inquiry and/or were not profiled in the report. Understanding whose voices are being represented can help in further examining the lived experiences of those individuals.

The report lacks a critical race lens applied to its research methodology, yet race should be a significant part of the analysis and can help in understanding racial disparities as they relate to the experiences of former CVGH residents (Twine and Warren, 2000). Masking racial identities of participants insinuates that all former residents were treated equally and by doing so assumes that racism could not have been a prevalent factor in the treatment of certain individuals. Despite claims of mistreatment and abuse of Indigenous children in non-Indigenous homes by the former residents as well as findings from the Kimelman inquiry that spoke of mistreatment and abuse during the Sixties Scoop, this report decided not to hear or imagine the possibility. In fact, the CVGH report did not mention the Sixties Scoop at all. In denying such 
terms as Sixties Scoop and withholding the identity of the former group home residents, while naming and contextualizing Mr. Blake as a "John Wayne character", the report upholds certain iconic narratives that privilege the experiences of non-Indigenous peoples all the while masking Others who are subjected to racialization, colonization, and imperialism.

In scope, objective, and overall methodology, all respondents were considered "equal" in how this report proceeded to validate certain stories over Others and acknowledging certain histories and experiences versus Others. To illustrate, Resident "U" was strategically placed last in the order of participant profiles and perhaps is reflective of how his story was viewed, judged and ultimately left unexamined. In fact, most stories deemed unpleasant throughout the report were not fully explored, or were invalidated as lacking sufficient evidence to prove, specifically those including allegations of sexual abuse, physical abuse, and slave labour.

\section{Exploitation}

A frequent visitor to the Blake Home who helped out from time to time and who accompanied the residents several times on camping trips referred to Mr. Blake's "circle of ridicule." He said the residents would sit in a circle and a resident who had displayed bad behaviour would be disciplined in front of the others. He felt it was humiliating. He also felt that Mr. Blake thought there was a difference between aboriginal and nonaboriginal boys and that non-aboriginal boys were better. He also said that Mr. Blake was not anti-aboriginal and that there were beads and leather craft in the home and a totem pole that was erected on the property. He said that Mr. Blake favoured boys who were good. He said physical punishment occurred at the home. (Tuckett, 2010, p.17-18)

Throughout the CVGH report, much evidence suggested that the former children and youth residents feared the group home operator. One individual interviewed claimed that "Mr. Blake would blow a whistle when it was time to go and the residents would come running" (Tuckett, 2010, p.18). The school bus driver for the former residents was given authorization by the group home operator to stop any fighting by using physical force such as punching. According to the report, "most said, however, that he was a very strict disciplinarian" (, p.19). Residents noted in the CVGH report discuss in detail how various human rights violations occurred. Included among some of the testimonials of former residents are accounts of lickings, strappings, being "worked like dogs" on farms, sleeping on cement floors and incidences of sexual abuse amongst the children and youth. Moreover, they were prevented from speaking their Indigenous language. Upon release from the group home, one participant recalls getting dropped off in the city of Winnipeg without money, shelter or social supports, forcing him into homelessness.

Eventhough the report denies the fact that slave labour and exploitation occurred within the $\mathrm{CVGH}$, the report does speak to the harm that some former children and youth residents 
faced emotionally "by this strict militaristic and disciplined environment that used corporal punishment as a means to instill fear and control over its residents" (Tuckett, 2010, p.60). There is an overwhelming consensus regarding the fear that was instigated by the group home operator and felt by many of the children and youth that resided at the CVGH. There is also a recognition that the children and youth assisted farmers and the group home operator in laborious activities that brought economic benefits to Henry Blake. What is not clear is the extent to which the children and youth benefitted, if at all, from such extensive laborious activity. According to the International Labour Organization, it is unacceptable for children and youth to be forced into an activity that "is mentally, physically, socially or morally dangerous and harmful to children; and interferes with their schooling by: ...requiring them to attempt to combine school attendance with excessively long and heavy work" (International Labour Organization,1999).

Although the report profiles a number of former residents, there are many others that are not located and others (Indigenous peoples) who have faced similar experiences in other group homes in Manitoba. This report is telling in the form of knowledges that are legitimated and given space, while others are devalued and minimized. The CVGH report is decontextualized and does not confront issues of race, violence, sexual and emotional abuse. Further, what remains unacknowledged are the potential linkages with those Indigenous children and youth who died at $\mathrm{CVGH}$ as a result of the trauma endured. The profiles of the former Indigenous children and youth who resided at CVGH speak to the dire need for support, healing and redress.

\section{Justice}

“As a Sto':lo woman I do not think I cannot fully experience justice until we have reclaimed, revitalized, re-centred and once again become responsible to our Sto': lo ways of "being" (Victor 2007, p.15).

In examining ways forward, I look to Sto':lo scholar Wenana Victor in her description of justice (ibid). Victor outlines four main themes that have helped in her journey to decolonization involving resistance, recovering, reclaiming and revitalizing (ibid). Indigenous peoples have survived and endured despite attempts of assimilation, exploitation and oppression. Resistance requires coming to terms with historical contexts of colonization and how this has impacted Indigenous peoples on a personal, family and community level (ibid). This phase could involve the sharing of stories from those who have survived, but also the acknowledgment and a remembering of those who have not. Stories of resiliency would emphasize the barriers that Indigenous peoples have overcome within the child welfare system. These stories could be shared in group settings with other survivors or individually with Elders and/or counselors.

Although an apology was made to former residents of the CVGH, the apology lacked intent, understanding or acknowledgment that reflects Indigenous experiences of exploitation, physical and sexual abuse. An apology is a dialogue that entails an understanding of the harms 
that were experienced by those who were mistreated. In the apology offered by the province of Manitoba (Tuckett, 2010), the report lacked an understanding of what the former Indigenous residents had experienced and what other Indigenous children and youth were experiencing in Manitoba during the Sixties Scoop. With that said, an apology that takes into consideration the highly raced and oppressive position many Indigenous peoples were facing could help in acknowledging the 'wrongs' that occurred and potentially lead to recovery, healing and reconciliation.

As the Convention on the Rights of the Child (1990) speaks to the principle of child participation and voice (Article 12) and ensuring that Indigenous children are afforded the right to practice their culture and language in their communities (Article 30); it is integral that reclaiming and revitalizing are key to the healing process. Reclaiming "space, place, mind, body, spirit, culture, traditions, and history"; and revitalization speaks to "breathing life into our communities, returning to teachings, honoring our ancestors" (Victor, 2007, p. 3). These phases are characterized by healing, culture and community. Although many survivors of the Sixties Scoop are on this journey, Sam McGillivary has spoken to the need for greater supports to assist those that were separated from their families and placed in group homes such as compensation and restitution that can be put towards a centre where survivors can access spirituality and cultural programming as well as other sources of support. The Sixties Scoop meant separation between children and their ancestral territories, community and family. Although many survivors are already in the phase of reclaiming and revitalizing, financial compensation can help to assist their return to the space and place of their ancestors.

\section{Conclusion}

The Indigenous residents of the CVGH not only faced oppression through their experiences within the home, they were marginalized later through the report's privileging of certain types of (white) narratives. By situating the group home outside narratives of the Sixties Scoop, the CVGH report distorts and decontextualizes the realities of what was transpiring on a large scale within the province. By de-racing participants' identities through its profiles, the report treated all group home residents as equal, as though rac(ism) did not exist or play a role within the lives of the Indigenous residents. Race did and continues to play a major role in what voices are heard and how stories are contextualized versus how Others are rendered invisible. I would also argue that racism was a large contributor to the trauma, exploitation and abuse experienced by the former Indigenous residents at the CVGH. It is important to acknowledge the trauma inflicted and remember those that have not survived. An apology must find relevant ways of reconciliation and redress that take into consideration the lived experiences of those who have been marginalized. 
Notes

i A foster group home according to Hirschbach (1965) are "group homes for children" described as "in a house owned or rented by foster parents" (p.4).

ii The term(s)"un/name" plays upon certain tensions of hypervisibility and invisibility of Indigenous peoples within the report. Examples include the un-naming of the Indigenous residence and the history of the sixties scoop, and the naming of the warriors of the lost boys, their claims of abuse, as well as the naming of trauma that was caused by the former Indigenous resident that killed Mrs. Blake. The reference points to how some things are selectively both named and left unmarked.

\section{References}

Brodbeck, T. (2008, June 29). "A Form of Slavery". The International Child and Youth Care Network. Retrieved from http://www.ohchr.org/EN/ProfessionalInterest/Pages/CRC.aspx

Convention on the Rights of the Child, Sept. 2, 1990, Retrieved from http://www.ohchr.org/EN/ProfessionalInterest/Pages/CRC.aspx

Fournier, S., and Crey, E. (1997). Stolen From Our Embrace: The Abduction of First Nations Children and the Restoration of Aboriginal Communities. Vancouver, B.C.: Douglas \& McIntyre Ltd.

Gosek, T. (2008, July 1). "Small Victory for the Warrior of the Lost Boys". Grassroots News.

Government of Canada. Auditor General of Canada (2008). Chapter 4 - First Nations Child and Family Services Projgram, Indian and Northern Affairs Canada. Retrived from http://www.oag-bvg.gc.ca/internet/English/parl_oag_200805_04_e_30700.html

Hawthorn, H. B. (1966). A survey of the contemporary Indians of Canada: A report on economic, political, educational needs and policies. Ottawa: Indian Affairs Branch.

Hepworth, P.H. (1985). "Child Neglect and Abuse”. In Levitt, K.L., \& Wharf, B. eds. The Challenge of Child Welfare. 28-52. Vancouver: University of British Columbia Press.

Hepworth, P.H. (1985). "Substitute Care: The Range of Responses”. In Levitt, K.L., \& Wharf, B. eds. The Challenge of Child Welfare.142-159. Vancouver: University of British Columbia Press.

Hirschbach, E. (1965). Group homes for children. Ottawa: Canadian Welfare Council, Family and Child Welfare Division.

International Labour Organization. (1999) What is Child Labour. Geneva, Switzerland. Retrieved from http://www.ilo.org/ipec/facts/lang--en/ 
Johnston, P. (1983). Native children and the child welfare system. Canada Council on Social Development. Toronto: Lorimer.

Kimelman, E.C. (1985). Review committee on Indian and Métis adoptions and placements. Transcripts and briefs: public hearings, special hearings (and) briefs. Winnipeg, MB: Manitoba Community Services.

Kimelman, E. C. (1985). No quiet place: Review committee on Indian and Métis adoptions and placements. Final report to the Honourable Muriel Smith, Minister of Community Services. Winnipeg, MB: Manitoba Community Services.

Kusch, L. (2010, January 15). "Group Home Residents Get Quick Apology”. Winnipeg Free Press. Retrieved from http://www.winnipegfreepress.com/local/group home-residentsget-quick-apology-81662087.html

Larocque, E. (2004). "When the "Wild West" Is Me". In Rasporich, B.J. and Felske, L.W. Challenging Frontiers: The Canadian West. (pp.134-153). Calgary: University of Calgary Press.

"Lawsuit Filed Over Alleged Abuse at Group Home". (2011, March 14) The Canadian Press. Retrieved from http://www.cbc.ca/news/canada/manitoba/lawsuit-filed-over-allegedabuse-at-group home-1.1063990

“'Lost Boys' will get an independent review”. (2008, June 26) The Canadian Press. Retrieved Manitoba Family Services. (2016, February 4). Retrieved from http://www.gov.mb.ca/fs/childfam/cathedral_valley.html

Milloy, J.S. (1999). A National Crime: The Canadian Government and the Residential School System, 1879 To 1986. Winnipeg, Manitoba: The University of Manitoba Press.

Obomsawin, A. (1986). Richard Cardinal: Cry from a Diary of a Métis child [Documentary video]. National Film Board of Canada.

Ouston, R. (1994, August-September). “Adoption as Exploitation”. Pacific Current (Vancouver). 20. from http://winnipeg.ctvnews.ca/lost-boys-will-get-an-independentreview-1.304937

Razack, S. (2002). Race, Space, and the Law: Unmapping a White Settler Society. Toronto: Between the Lines.

Smith, L.T. (1999). Decolonizing Methodologies: Research and Indigenous Peoples. London \& New York: Zed Books Ltd. Dunedin: University of Otago Press.

Sindelar, R. (2004). Negotiating Indian Identity: Native Americans and Transracial adoption. Unpublished Master's Thesis. Loyala University Chicago. 
Stefancic, J. and Delgado, R. (2001) Critical Race Theory: An Introduction. New York University Press.

Swidrovich, C. (2004). Positive experiences of First Nations Children in non-Aboriginal foster or adoptive care: Deconstructing the "Sixties Scoop." Unpublished Master's Thesis. University of Saskatchewan, Saskatoon.

Twine, F.W. (2000). "Racial Ideologies and Racial Methodologies". In Twine, F.W., \& Warren, J.W., Racing Research, Researching Race: Methodological Dilemmas in Critical Race Studies, 1-34. New York University Press.

Tuck, E. and Yang, W.K. (2012). "Decolonization is not a metaphor". Decolonization: Indigeneity, Education \& Society, 1 (1), 1-40.

Tuckett, B. (2010). A Report on the Independent Review of Cathedral Valley Group Home. Submitted to the Honourable Gordon Mackintosh Minister of Family Services and Consumer Affairs, Province of Manitoba.

Turenne, P. (October 2011). “Gov't: Group Home Trauma Not Our Problem”. Toronto Sun. Retrieved from http://www.torontosun.com/2011/10/24/gov-were-not-responsiblefor-group home-trauma

Turenne, P. (2008, May 29). "Man to sue province over lifelong trauma”. Winnipeg Sun.

Turenne, P. (2008, June 16). "Grand Chief Calls for foster home inquiry”. Winnipeg Sun.

Victor, W. (2007). "Indigenous Justice: Clearing Space and Place for Indigenous Epistemologies". National Centre for First Nations Governance.

Walmsley, C. (2005). Protecting Aboriginal Children. Vancouver, British Columbia: UBC Press.

Welch, M.A (2008, June 16). "Fontaine calls for inquiry into plight of "lost boys"”. Winnipeg Free Press.

Wilson, S. (2008). Research Is Ceremony. Winnipeg, Manitoba: Fernwood Publishing. 